\title{
Pengaruh Sisipan Resonator Celah Sempit pada Serapan dan Respon Spasial Quadratic Residue Diffuser
}

\author{
Erna Y. Devitasari, ${ }^{*}$ Arifatul Chorida, Eki Muqowi, Nining Haryanti, Harjana, dan Iwan Yahya ${ }^{\dagger}$ \\ Laboratorium Riset Akustik (iARG) Jurusan Fisika, \\ FMIPA- Universitas Sebelas Maret (UNS) \\ Jl. Ir. Sutami 36A Kentingan, Surakarta 57126
}

\begin{abstract}
Intisari
Telah dilakukan analisis pengaruh sisipan resonator celah sempit terhadap perubahan kinerja serapan dan respon spasial quadratic residue diffuser (QRD). Pengujian serapan elemen diffuser dilaksanakan dengan menggunakan teknik tabung impedansi dua mikrofon, sementara simulasi respon spasial dikerjakan dengan menggunakan perangkat lunak AFMG Reflex pada tiga kondisi sisipan berbeda. Hasil pengujian menunjukkan bahwa sisipan resonator celah sempit pada rancangan standar QRD dapat memicu peningkatan koefisen serapan yang bersifat akumulatif dan berdampak pada peningkatan respon spasial omnidireksional pada bentang frekuensi tinggi di atas $800 \mathrm{~Hz}$. Sifat yang demikian menunjukkan bahwa modifikasi QRD standar dengan sisipan resonator celah sempit memiliki potensi yang sangat baik untuk aplikasi pada ruangan dimana terdapat kebisingan yang bersumber dari mesin atau piranti yang mengandung komponen yang berputar (rotating machinery).
\end{abstract}

\begin{abstract}
The influence of slit-like resonator on the sound absorption coefficient and spatial response of quadratic residue diffesr has been done both by experimentally and computer simulation. Laboratory work has been done by using impedance tube technique refer to ASTM E-1050-98 for measuring the sound absorption coefficient of the diffuser element, while AFMG Reflex has been utilized for simulation purposes. The results shows that slit like resonator insertion bring accumulative increment of the sound absorption coefficent on the high frequency range above $800 \mathrm{~Hz}$. In addition, a significant omnidirectional spatial response also occur when the slit-like resonator is inserted into standar QRD. Those phenomenon not occured on the lower frequency band due to the resonator depth that very small compared to the wavelength of the waves at low frequency band.
\end{abstract}

KATA KUNCI: QRD, slit-like resonator, sound absorption, spatial response.

\section{PENDAHULUAN}

Pemakaian diffuser untuk maksud peningkatan kualitas akustik ruangan telah berlangsung dalam waktu relatif lama khususnya untuk pengendalian bunyi di frekuensi rendah. Prinsip kerja diffuser berkaitan dengan reduksi fraksi energi gelombang yang dipantulkan secara spekular akibat adanya sebagian energi bunyi yang dihamburkan oleh permukaan benda seperti tersaji pada Gambar 1.

Sifat menghamburkan bunyi dari suatu bahan atau struktur akustik dicirikan oleh besaran koefisien hamburan yang nilainya diberikan oleh hubungan [1],

$$
S=\frac{\alpha_{\text {spek }}-\alpha_{s}}{1-\alpha_{s}}=1-\frac{E_{\text {spek }}}{E_{\text {total }}}
$$

\footnotetext{
*E-MAIL: ernayunitadevitasari@gmail.com

$\dagger$ E-MAIL: iwanyy@yahoo.com
}

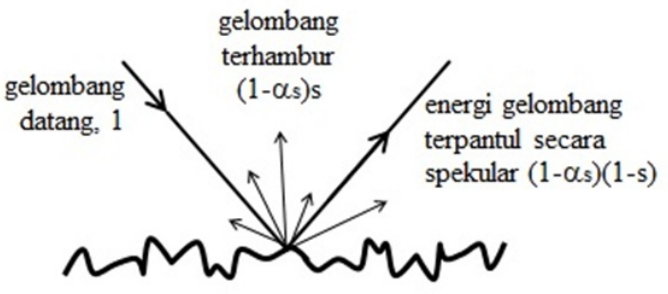

Gambar 1: Hamburan bunyi oleh permukaan kasar [1].

dengan $\mathrm{E}_{\text {spek }}$ dan $\mathrm{E}_{\text {total }}$ berturut-turut merupakan energi bunyi yang terpantul secara spekular dan energi total menurut persamaan,

$$
E_{\text {spek }}=\left(1-\alpha_{s}\right)(a-s)=\left(1-\alpha_{\text {spek }}\right)
$$

dan

$$
E_{\text {total }}=1-\alpha_{s}
$$




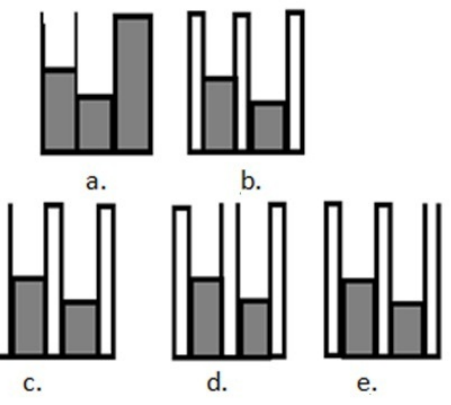

Gambar 2: Model elemen diffuser yang digunakan dalam pengujian serapan:(a) elemen standar, (b) elemen standar dengan resonator tertutup, (c) sisipan di $\mathrm{n}=0$, (d) sisipan di $\mathrm{n}=2$, dan (e) sisipan $\mathrm{n}=$ 4.

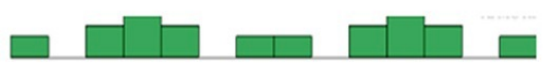

(a)

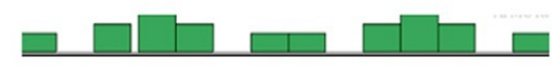

(b)

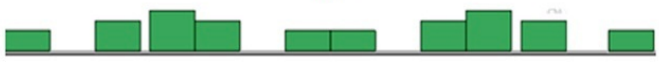

(c)

Gambar 3: Struktur diffuser yang digunakan dalam simulasi, (a) konfigurasi standar QRD N:14, (b) diffuser dengan sisipan tunggal pada elemen ke $\{3\}$ sehingga QRD berubah menjadi N:15, (c) adalah sisipan simetrik pada $\{3,12\}$ membentuk QRD N:16.

dalam hal ini s merupakan koefisien hamburan, $\alpha_{s}$ adalah koefisien serapan, dan $\alpha_{\text {spek }}$ adalah koefisien serapan spekular semu.

Ragam diffuser telah berkembang pesat. Modifikasi permukaan umumnya menjadi teknik yang dipilih untuk tujuan optimasi kinerja serapan [2-4]. Pendekatan lain untuk tujuan modifikasi orientasi hamburan telah pula berkaembang. Diantaranya adalah dampak penempatan sejumlah silinder di depan diffuser dan variasi konfigurasi diffuser jamak terhadap efek difusi dan hamburan yang terjadi $[5,6]$.

Paper ini menyajikan hasil dari modifikasi desain yang berbeda yakni pengaruh sisipan resonator celah sempitseperempat panjang gelombang terhadap perubahan pola hamburan dan kinerja serapan bunyi elemen diffuser. Pilihan pada pemakaian resonator celah sempit didasarkan pertimbangan fungsional dari rancangan yang dikembangkan. Sebagaimana halnya yang telah dilaporkan oleh Sadamoto and Murakami, resonator celah sempit memiliki kemampuan yang cukup efektif untuk mereduksi bising diskrit. Kategori bising seperti itu dapat ditimbulkan oleh peralatan industri atau mesin yang memiliki komponen kipas atau roda gigi yang berputar, termasuk di dalamnya kipas angin dan mesin pendingin udara [7].

Kajian dalam paper ini didasarkan pada respon struktur rancangan dasar berupa QRD. Kinerja serapan elemen diffuser dianalisis dengan teknik tabung impedansi menurut prosedur standar ASTM E-1050-98, sementara simulasipola hamburan,

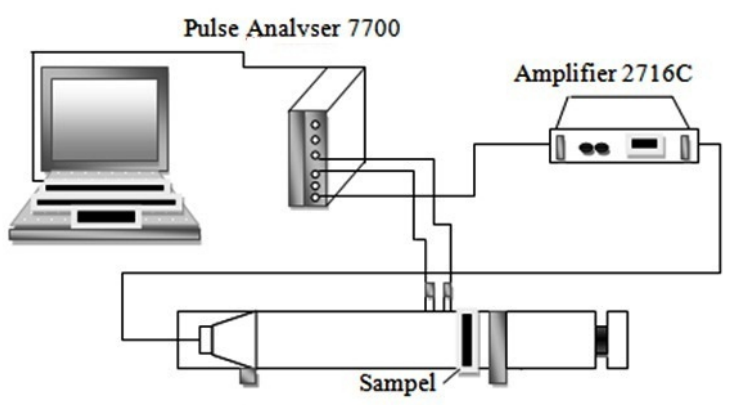

Tabung Impedansi dua mikrofon 4206

Gambar 4: Pengujian koefisien serapan bunyi elemen diffuser dengan prosedur ASTM E 1050-98.

perhitungan koefisien hamburan dan difusi dilakukan dengan menggunakan perangkat lunak AFMG Reflex [8, 9].

\section{METODE}

\section{Pembuatan Model Elemen Diffuser (Sebagai Data Pendukung)}

Model elemen diffuser disajikan dalam Gambar 2. Dalam hal ini sirip pada QRD standar dimodifikasi menjadi resonator. Dengan demikian, konfigurasi dasar QRD dengan tiga elemen berubah menjadi QRD termodifikasi dengan lima elemen dimana elemen pada posisi $\{0,2,4\}$ merupakan resonator celah sempit.

Elemen diffuser dibuat dari bahan kertas tebal dan kaku yang di pasaran dikenal dengan sebutan yellow board dengan ketebalan $0,2 \mathrm{~cm}$.

Spesifikasi elemen diffuser yang digunakan dalam eksperimen adalah sebagai berikut. Konfigurasi resonator celah sempit dan sumur diffuser standar yang membentuk diffuser termodifikasi dengan lima elemen berbentuk tabung persegi dengan ukuran panjang dan lebar yang sama sebesar $6 \mathrm{~cm}$ berketinggian $12 \mathrm{~cm}$. Lebar ketiga celah sempit adalah $0,8 \mathrm{~cm}$, sementara sumur diffusernya sendiri memiliki lebar $1,2 \mathrm{~cm}$ dengan kedalaman berbeda berturut-turut sebesar $7,5 \mathrm{~cm}$ dan 5 $\mathrm{cm}$ pada elemen $\{2,4\}$.

\section{Model Sintetik QRD}

Model yang digunakan dalam simulasi berupa struktur QRD dengan jumlah elemen $\mathrm{N}=14$ yang dibentuk dari konfigurasi perulangan pola dua buah diffuser sejenis dengan $\mathrm{N}=$ 7 sehingga diperoleh urutan kedalaman sumur diffuser adalah $\{46323644632364\}$.

Lebar elemen sumur diffuser adalah $5 \mathrm{~cm}$, sementara resonator celah sempit yang disisipkan memiliki lebar $1 \mathrm{~cm}$ dengan kedalaman seragam $6 \mathrm{~cm}$. Rancangannya disajikan pada Gambar 3. 


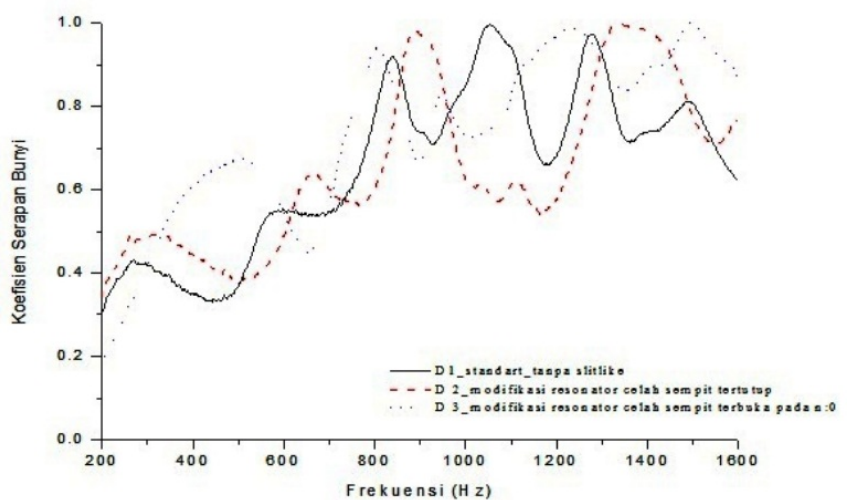

(a)

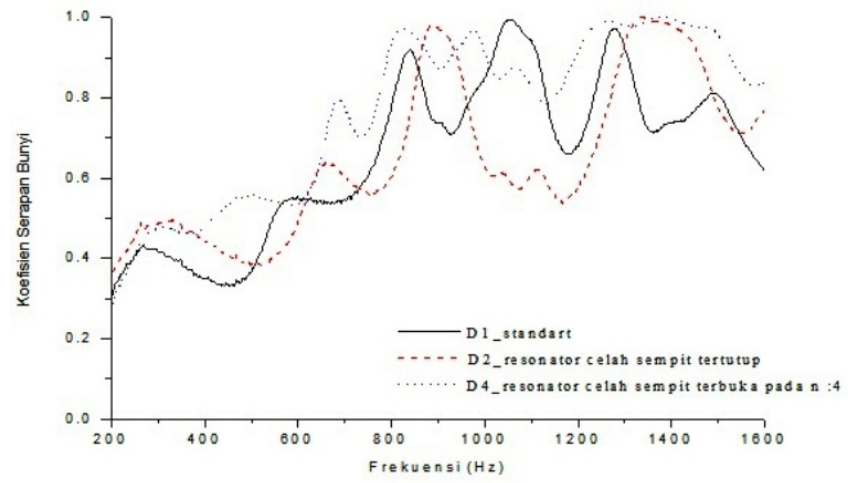

(b)

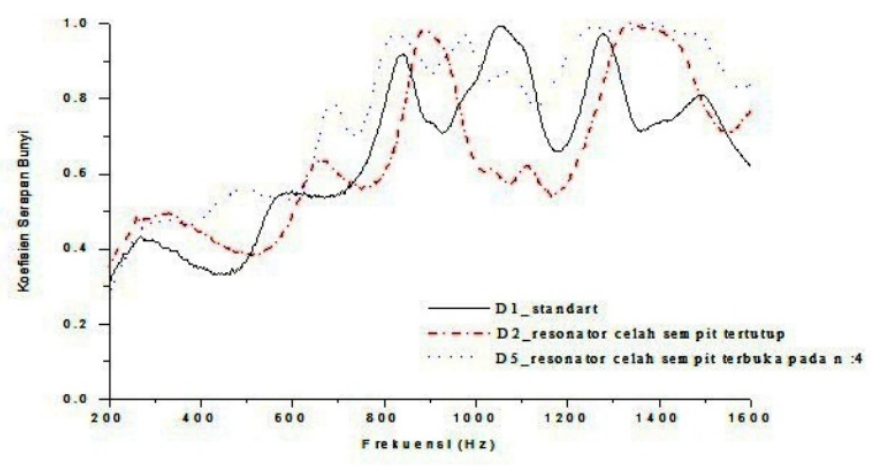

(c)

Gambar 5: Perbandingan koefisien serapan elemen difuser standar dengan rancangan yang telah dimodifikasi dengan sisipan resonator celah sempit tertutup dan dan tiga posisi resonator celah sempit terbuka.

\section{Pengujian Koefisien Serapan Bunyi}

Kinerja serapan elemen diffuser telah diuji di Laboratorium Riset Akustik (iARG) Jurusan Fisika Fakultas MIPA Universitas Sebelas Maret menggunakan tabung impedansi B\&K 4206 yang terkoneksi ke B\&K Pulse 3160-A-042. Adapun pengolahan data dilakukan dengan perangkat lunak B\&K Pulse 7700 versi 16 dan B\&K Material Testing.

Elemen diffuser ditempatkan di dalam tabung impedansi kemudian bunyi random dibangkitkan dari loudspeaker yang terletak di ujung tabung. Dua buah mikrofon B\&K 4187 digunakan untuk mengindera perubahan tekanan bunyi di dalam tabung. Sinyal dari kedua mikrofon tersebut kemudian diperkuat dengan amplifier B\&K 2716C lalu diolah dengan teknik analisis fungsi respon frekuensi untuk mendapatkan nilai koefisien serapan elemen diffuser yang diuji.

Nilai fungsi respon frekuensi $\mathrm{H}_{1}$ dari sinyal yang diindera oleh kedua mikrofon diberikan oleh hubungan,

$$
H_{1}=\frac{p_{2}}{p_{1}}=\frac{e^{j k \ell}+R e^{-j k \ell}}{e^{j k(\ell+s)}+e^{-j k(\ell+s)}}
$$

dalam hal ini $\mathrm{p}_{1}$ dan $\mathrm{p}_{2}$ merupakan tekanan bunyi yang terukur oleh mikrofon pertama dan kedua, $\ell$ adalah jarak permukaan sampel uji ke mikrofon pertama, dan s merupakan jarak antar mikrofon sebagaimana diilustrasikan di dalam Gambar 4.
Nilai koefisien serapan bunyi diberikah oleh,

$$
\alpha=1-|R|^{2}
$$

dengan R merupakan koefisien refleksi.

\section{Simulasi Hamburan}

Model sintetik QRD standar dan QRD yang dimodifikasi dengan sisipan elemen resonator berbentuk celah sempit dibangun menggunakan perangkat lunak AFMG Reflex. Hasilnya disajikan pada Gambar 3.

Dengan menggunakan model tersebut kemudian dilakukan analisis terhadap respon spasial rancangan pada orientasi sudut sebesar $0^{\circ}$ dan $-90^{\circ}$ terhadap sumberbunyi pada tiga frekuensi berbeda masing-masing $500 \mathrm{~Hz}, 1 \mathrm{kHz}$, dan $2 \mathrm{kHz}$.

\section{HASIL DAN PEMBAHASAN}

\section{Koefisien Serapan Bunyi}

Nilai koefisien serapan elemen diffuser disajikan pada Gambar 5. Dalam hal ini terdapat tiga kondisi pengujian 


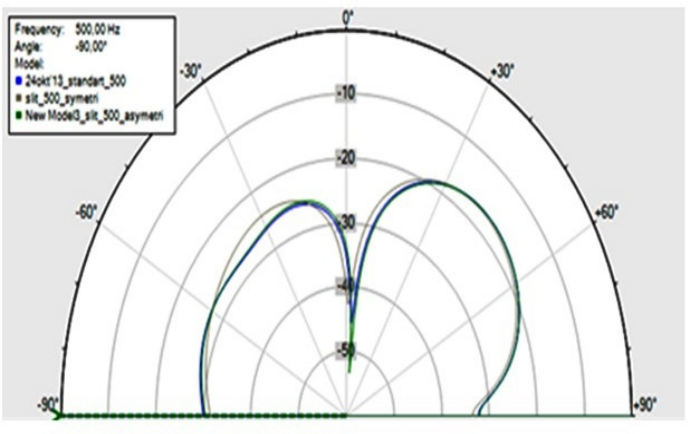

(a)

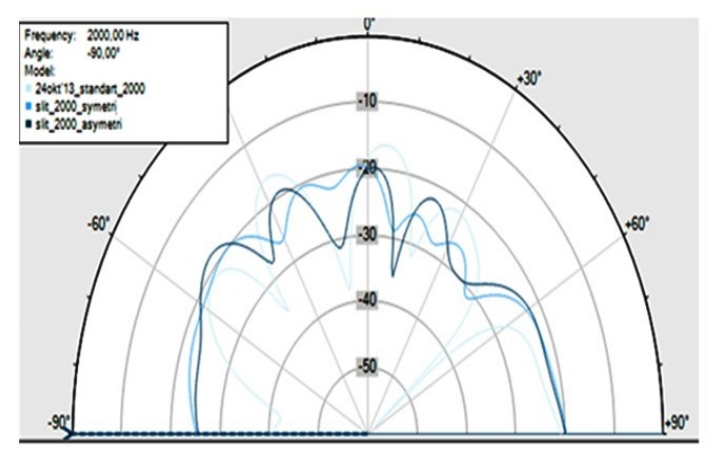

(c)

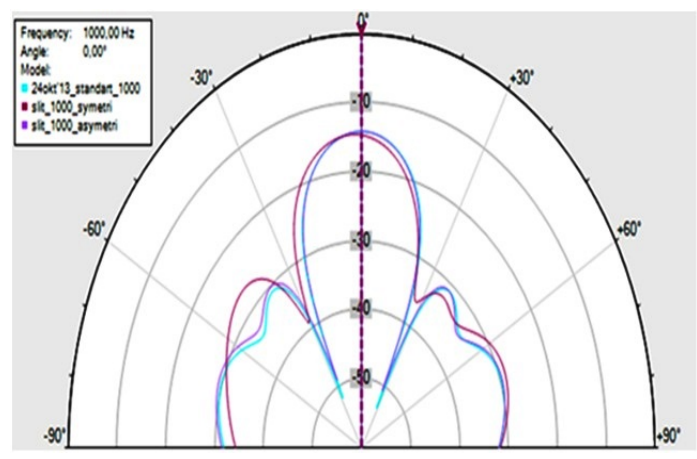

(e)

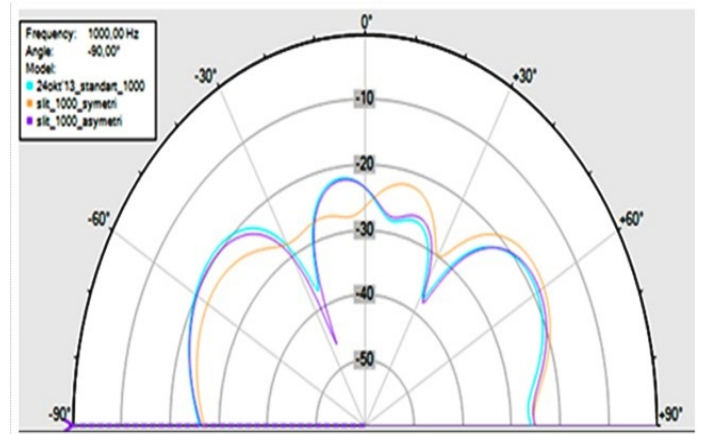

(b)

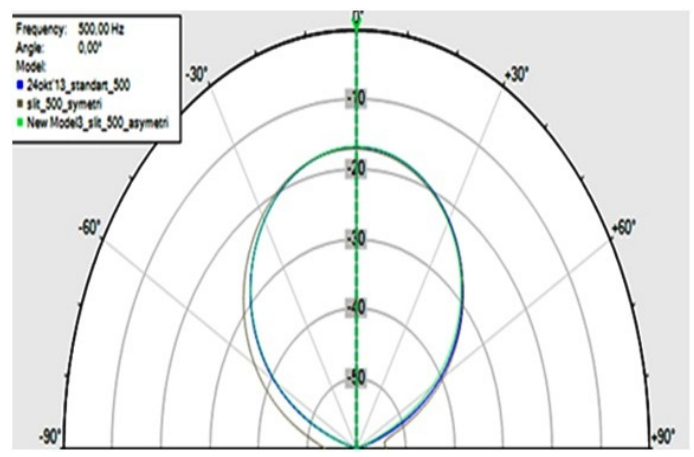

(d)

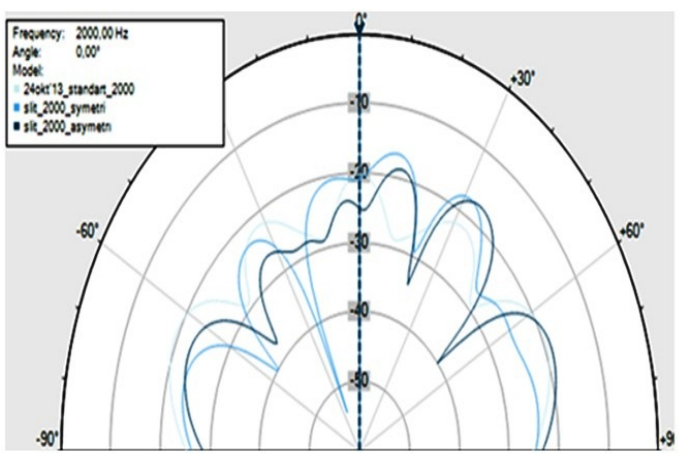

(f)

Gambar 6: Hasil respon spasial dari diffuser standart, modifikasi resonator celah sempit asimetri, dan simetri dengan variasi frekuensi dan sudut (a) $500 \mathrm{~Hz} /-90^{\circ}$, (b) $1 \mathrm{kHz} /-90^{\circ}$, (c) $2 \mathrm{kHz} /-90^{\circ}$, (d) $500 \mathrm{~Hz} / 0^{\circ}$, (e) $1 \mathrm{kHz} / 0^{\circ}$, (f) $2 \mathrm{kHz} / 0^{\circ}$.

berbeda berkait dengan penempatan resonator celah sempit pada konstruksi diffuser.

Ketiga plot pada Gambar 5 menyajikan perbandingan kinerja elemen diffuser standar (solid line), modifikasi berupa penggantian sirip dengan celah tertutup (dash line), serta koefisien serapan pada keadaan resonator celah sempit terpasang (dotted line).

Gambar 5(a), 5(b)dan 5(c) berturut-turut merupakan perbandingan koefisien serapan untuk tiga posisi berbeda sisipan resonator celah sempit yakni di n:0, n:2, dan n:4.

Dari ketiga plot tersebut tampak dua gejala yang menarik. Gejala pertama adalah bergesernya respon serapan yang semula berada di bentang frekuensi $800 \mathrm{~Hz}-1,1 \mathrm{kHz}$ pada elemen diffuser standar ke bentang frekuensi yang lebih tinggi 1,2 $1,6 \mathrm{kHz}$. Gejala yang sama juga terjadi pada bentang frekuensi lebih rendah yang semula berada di bentang $750-900 \mathrm{~Hz}$ pada diffuser standar menjadi $800 \mathrm{~Hz}-1 \mathrm{kHz}$ pada diffuser yang dimodifikasi dengan resonator tertutup.

Gejala kedua adalah peningkatan respon serapan yang bersifat konsisten tanpa terpengaruh posisi penyisipan resonator celah sempit terbuka. Tampak dari ketiga plot tersebut bahwa pergeseran respon di dua bentang frekuensi berbeda sebagaimana terjadi pada saat modifikasi dengan resonator tertutup berubah menjadi peningkatan respon serapan yang konsisten di atas 0,7 pada bentang frekuensi $560 \mathrm{~Hz}-1,6 \mathrm{kHz}$.

Dari kedua gejala tersebut tampak bahwa modifikasi sirip diffuser dengan resonator celah sempit tidak memberikan dampak yang signifikan pada perubahan serapan di frekuensi rendah pada bentang yang lebih kecil dari $600 \mathrm{~Hz}$. Hal ini dapat dipahami karena perubahan volume yang tidak begitu signifikan yang tidak dapat dapat memicu mekanisme resonansi di frekuensi rendah. 


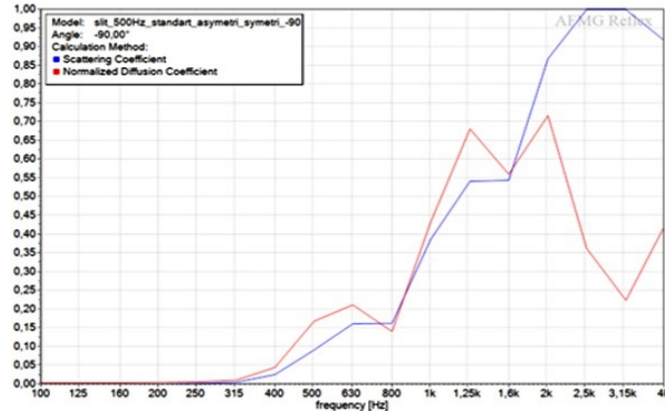

(a)

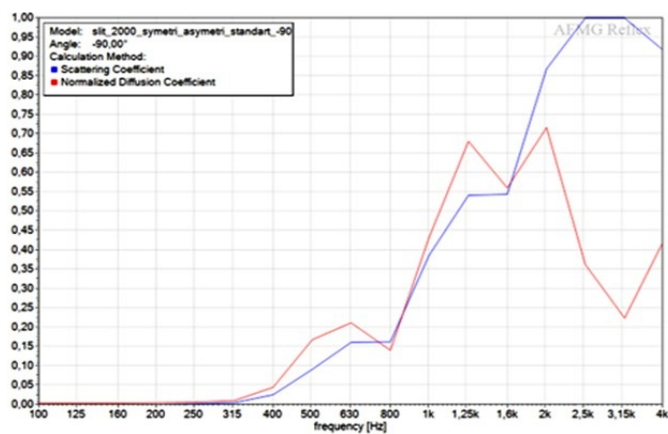

(c)

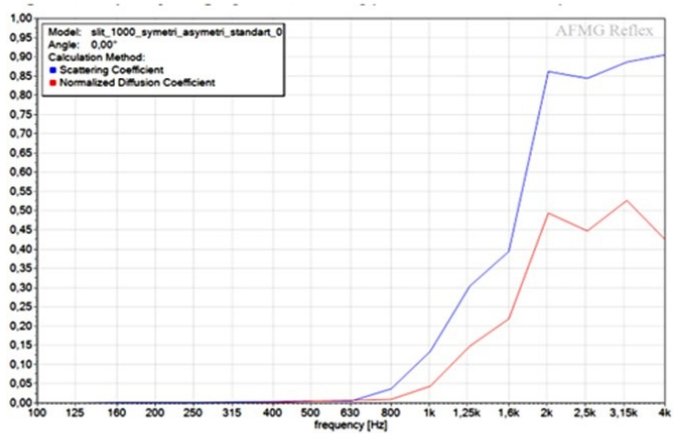

(e)

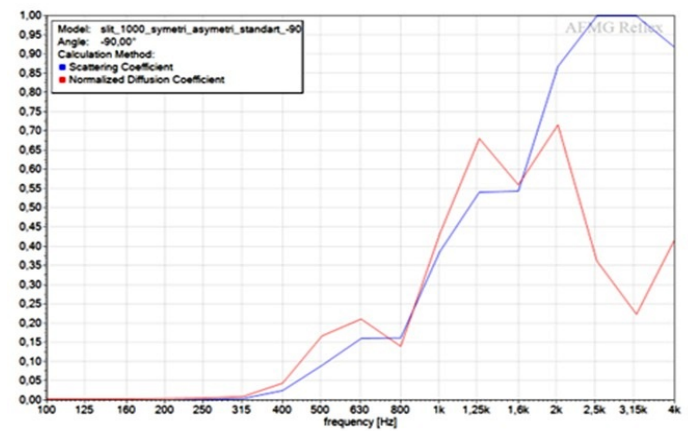

(b)

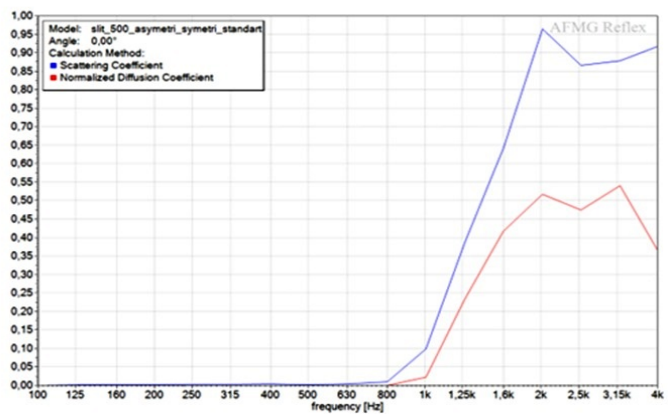

(d)

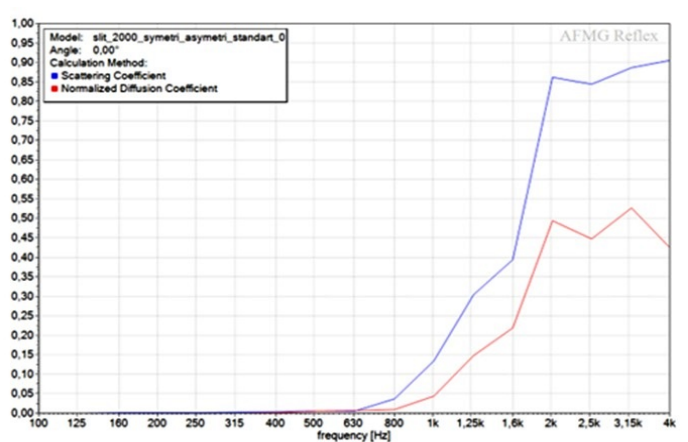

(f)

Gambar 7: Grafik hubungan antara nilai koefisien scattering dan koefisien normal difusi terhadap frekuensi dari software AFMG Reflex, (a) $500 \mathrm{~Hz} /-90^{\circ}$, (b) $1 \mathrm{kHz} /-90^{\circ}$, (c) $2 \mathrm{kHz} /-90^{\circ}$, (d) $500 \mathrm{~Hz} / 0^{\circ}$, (e) $1 \mathrm{kHz} / 0^{\circ}$, (f) $2 \mathrm{kHz} / 0^{\circ}$.

Adapun peningkatan serapan di bentang frekuensi yang lebih tinggi terpicu oleh dua hal berbeda. Pada modifikasi sirif dengan resonator tertutup, kenaikan serapan disumbangkan oleh penigkatan luas bidang serapan sebesar dua kali lipat dibandingkan dengan keadaan diffuser standar.

Sementara itu mekanisme berbeda terjadi pada saat resonator celah sempit disisipkan menggantikan sirip diffuser standar. Celah sempit yang terpasang memiliki respon sebagai resonator seperempat panjang gelombang yang menyebabkan peningkatan serapan yang bersifat akumulatif bersama mekanisme redaman viskous pada bentang frekuensi tinggi.

\section{Simulasi Hamburan}

Respon spasial untuk dua keadaan berbeda yakni orientasi $0^{\circ}$ dan $-90^{\circ}$ terhadap sumber bunyi disajikan pada Gambar 6 .
Gambar 6(a), 6(b) dan 6(c) adalah respon spasial $-90^{\circ}$ untuk ketiga ragam sisipan pada Gambar 3 yakni diffuser standar, sisipan pada satu sisi asimteri $\{n: 3\}$, dan sisipan simetri $\{n: 3,12\}$ untuk tiga frekuensi berbeda $500 \mathrm{~Hz}, 1 \mathrm{kHz}$, dan 2 kHz. Adapun Gambar 6(d), 6(e) dan 6(f) adalah respon spasial sejenis untuk orientasi $0^{\circ}$.

Dari keseluruhan sajian respons spasial pada Gambar 6 tampak bahwa dampak dari jumlah dan posisi sisipan resonator celah sempit memunculkanpola hamburan omnidireksional signifikan pada bentang frekuensi tinggi. Akibatnya koefisien hamburan meningkat pula di bentang frekuensi tinggi. Keadaan demikian teramati secara konsisten baik pada orientasi $0^{\circ}$ maupun $-90^{\circ}$ terhadap sumber bunyi.

Peningkatan nilai koefisien hamburan di bentang frekuensi tinggi memberikan penjelasan yang menguatkan penjelasan tentang mekanisme pemicu bertambahnya nilai koefisien ser- 
apan pada frekuesni tinggi di atas $800 \mathrm{~Hz}$ sebagaimana yang diperoleh dalam pengujian menggunakan tabung impedansi.

Perubahan minor pada respon spasial frekuensi rendah berkaitan dengan mekanisme perambatan gelombang pada resonator celah sempit yang digunakan. Dalam hal ini ukuran kedalaman resonator tidak memenuhi kaidah seperempat panjang gelombang yang dapat memicu pembalikan fase pada bentang frekuensi rendah. Sehingga dapat dipahami bahwa perubahan respon omnidireksional hanya teramati pada bentang frekuensi tinggi.

Pada Gambar 7 terlihat secara keseluruhan bahwa kinerja difusi normal pada sudut $-90^{\circ}$ dengan hasil respon spasial pada frekuensi $2 \mathrm{kHz}$ lebih tinggi dibandingkan sudut 0 ? sebesar 0,716 pada frekuensi $2000 \mathrm{~Hz}$. Sedangkan untuk kinerja nilai koefisien scattering sebesar 0,999 pada frekuensi 2500 $\mathrm{Hz}$ dan $3150 \mathrm{~Hz}$ dengan sudut $-90^{\circ}$.

\section{SIMPULAN}

Berdasarkan hasil simulasi dan pengujian di laboratorium terhadap elemen diffuser yang dikembangkan, dapat disim- pulkan bahwa teknik sisipan resonator celah sempit dapat memberikan peningkatan kinerja serapan yang bersifat akumulatif dan signifikan serta pada saat yang bersamaan dapat memunculkan respon spasial omnidirectional yang baik pada bentang frekuensi tinggi. Dengan demikian dapat dikemukakan bahwa rancangan diffuser dengan sisipan resonator celah sempit memiliki potensi yang baik untuk aplikasi pada kondisi dimana terdapat bising freskuensi tinggi yang ditimbulkan oleh mesin atau peralatan industri yang memiliki komponen berputar berbentuk kipas atau roda gigi. Dapat disimpulkan bahwa Berdasarkan hasil penelitian modifikasi resonator celah sempit mempengaruhi nilai koefisien serapan bunyi pada frekuensi tertentu. Pada frekuensi rendah dan tinggi diffuser dengan variasi resonator celah sempit nilai koefisien serapan bunyinya lebih baik daripada diffuser standart.
[1] T.J. Coc and P.D. Antonio, Acoustics Absorbers and Diffusers, Theory, Design and Application (Spon Press, 2004).

[2] T.J. Cox, J. Acoust. Soc. Am., 97 (5), 2928-2941 (1995).

[3] T.J. Cox, J. Audio Eng. Soc, 44, 354-356 (1996).

[4] I. Yahya and Harjana, New sound absorption improvement strategy for QRD element, Proceeding of $20^{\text {th }}$ International Conference on Sound and Vibration, ICSV20, Bangkok, July 2013.

[5] M.A. Pogson., et al., J. Acoust. Soc. Am., 128 (3), 1149-1154 (2010).

[6] Y. Jianbin., S. Yong, and Wang H, J. Acoust. Soc. Am., 119,
3546-3548 (2006)

[7] A. Sadamoto., Y. Murakami, International Journal of Rotating Machinery, 9, 239-246 (2003).

[8] ASTM E 1050-98, Standard Test Method for Impedance and Absorption of Acoustical Materials Using Tube, Two Microphones and A Digital Frequency Analysis System, (American Society for Testing and Materials, 1998).

[9] AFMG Reflex, New Tools for the Design and Application of Diffuser, 2011. 